\title{
The development mechanism and control technology visual- ization of the vault cracks in the ancient underground cavern of Longyou
}

\author{
${ }^{1}$ Xi' an University of Science and Technology, Xi' an 710054, China; *Corresponding author, E-mail: gbl8001@126.com \\ ${ }^{2}$ Institute of Geology and Geophysics, Chinese Academy of Sciences, Beijing, 100029, China \\ ${ }^{3}$ Longyou Grottoes Research Institute, Zhenjiang, 324400, China \\ ${ }^{4}$ Longyou county tourism committee, Zhenjiang, 324400, China
}

(Received: August 15, 2018; Revised accepted: October 23, 2019)

https://doi.org/10.18814/epiiugs/2019/019023

The ancient underground cavern of Longyou has a history of more than 2,000 years, and it exhibits a considerable value in archeology, history, science, and culture; therefore, its protection is of considerable significance. Investigating the development mechanism of vault cracks is an important part of the protection work. Most previous studies have been conducted from a single perspective. For an in-depth study, a multi-factor approach is used to conduct comprehensive research based on mechanical analysis and monitoring analysis. The analysis shows that the vault cracks continue to expand and uneven settlement of vault increases gradually. Theoretical analysis and monitoring exhibit similar trends, which indicates that the vault is considerably damaged; therefore, a reinforced support technology is necessary. In this study, the Building Information Modeling (BIM) technology is considered for application to an ancient underground cavern. It has the potential to provide new ideas and visual materials to investigate and conserve the ancient underground cavern of Longyou. In addition, it would promote the wider application of the BIM technology in geotechnical engineering.

\section{Introduction}

The Fenghuang Mountain group of ancient caverns is one of the three major components of the ancient underground cavern system of Longyou, which is located in Longyou County, Zhejiang Province, china. It is located on a small hill called the Fenghuang Mountain on the north bank of the Qujiang River, $3 \mathrm{~km}$ north of Longyou County. There are 24 ancient caverns distributed within $0.38 \mathrm{~km}^{2}$ of the mountain. This group of ancient caverns is large in scale and densely distributed, which gives rise to potential problems (Yang et al., 2000; Yang et al., 2003). In 1992, four local villagers drained the so called "Bottomless Pond" in the village. After 17 days and nights a magnificent underground cavity referred to as the No. 5 cavern was revealed to the world. According to studies by archaeologists, the excavation of these ancient caverns began in the Western Han Dynasty, which exhibits a history of more than 2,000 years. The scale, structure, and regular chisel marks of the caverns have startled the world. Additionally, owing to the value of the cultural relics and their significance to science and technology, the caverns have attracted the attention of several scientific researchers (Huang, 2006; Tanimoto, 2006; Yang, 2005). Wang (2001) made an evaluation of this "a marvelous creation excelling nature" after an expedition to the ancient underground cavern of Longyou. Clearly, in terms of age, artistic value, and science and technology, the ancient project of Longyou compares favorably with other famous ancient underground projects, e.g., "Bet-Guvrin," an ancient stone quarry in Israel, and "Wieliczka," an ancient salt mine in Poland. However, the ancient caverns have been damaged in varying degrees by various factors.

The caverns are located in the central part of the Jinqu Basin, where the strata are observed to be monolithic. They are within the Upper Cretaceous Quxian formation, and the lithologies are brick-red thick layered argillaceous siltstone sandstones. This type of rock exhibits low hardness and loose structure and is easily weathered. The caverns have characteristics of artificial construction, large span, and ultra-shallow burial. Due to tourism development, the ancient caverns have undergone huge environmental changes to transform them from being filled completely with water to no water. The ancient underground caverns are affected due to changes in the humidity of the ground surface and groundwater, and they are obviously affected by weathering, human activities, and periodic temperature changes. After conducting an observation, it was established that vault shedding exists in caverns No. 12, 18, and 24 and that the vault of cavern No. 24 has collapsed. Additionally, a few cracks have been observed on the vault of cavern No. 2, which have extended and expanded. Due to joints cutting the vault of the cavern this can collapse at any time. The vault of cavern No. 3 also contains cracks, and there is a dangerous rock mass with three sides hanging in the air, which continues to deteriorate.

Therefore, to ensure long-term stability of the cavern, investigating the mechanism of vault cracks is of considerable importance. If the causes of vault cracks can be analyzed from different perspectives, it 
will be beneficial to effectively control the direction, length, and width of crack development and will play a vital role in the long-term protection of the cavern.

Several scholars have investigated the expansion of vault cracks in the ancient underground cavern of Longyou; however, their conclusions still need to be improved. The excavation method of the Longyou ancient cavern is similar to bord and pillar-type mining in coal mines. The main causes of coal mine roof damage are the large span, high horizontal stress, and small pillars (Gregory et al., 2001). Similar factors exist in the ancient underground caverns of Longyou and lead to cracks in the vault of the caverns to a certain extent. Based on three-dimensional (3D) numerical calculation, Li Lihui used Fast Lagrangian Analysis of Continua in 3D (FLAC3D) to analyze the stress characteristics of the vaults in the Longyou ancient cavern (Li et al., 2005a). Zhu Jiewang analyzed the cracking mode and characteristics of the vault in cavern No. 1 from the perspective of engineering mechanics (Zhu et al., 2009). These studies have laid the foundation for subsequent studies; however, each study has been simultaneously conducted from a single perspective. The causes of development of the cracks needs to be studied from many aspects, rather than through a single factor or method. The causes of cracks in different areas of the cave are also different. So far, the analysis of mechanics, approximate structural form and numerical calculation has been carried out from a single aspect and the related research factors are also onesided. Therefore, these methods cannot comprehensively analyze the causes of vault cracks. Based on the actual location of the cavern, the factors affecting the stability of the cavern, the structural stress and displacement changes of the cavern should be combined to comprehensively analyze the crack development mechanism. The coupling analysis of force field, temperature field, crack, weathering and other factors will be carried out to ensure the long-term stability of the caves through further research. This study will continue to analyze the causes of vault crack development from the perspective of rock mechanics and ancient cavern environment. The following two methods have been proposed to investigate the aforementioned crack expansion mechanism. First, the factors that cause crack expansion will be analyzed. Second, the principle of crack generation on the vault will be analyzed based on the aspects of rock mechanics and fracture mechanics and the reliability will be verified by combining with the monitoring data. At the same time, the application of Building Information Modeling (BIM) technology to the reinforcement measures of the caverns has considerable theoretical significance and engineering application value to ensure further protection of the ancient underground caverns of Longyou.

\section{Project Overview}

The Fenghuang Mountain group of ancient caverns comprises 24 caverns (Fig. 1). Cavern Nos. 1-5, which have been developed for tourism, experience varying degrees of deformation and damage due to various factors, e.g., separation of vault stratified rock and falling of the blocks, cracks occur in both pillars and vaults, and the increasingly severe weathering of the surrounding rocks and rock pillars The cracks in the vault are observed to expand quickly. The vault of each cavern is a sloping structure, the vault slope of cavern Nos. $1-3$ is $\mathrm{NE} 10^{\circ}-\mathrm{NE} 26^{\circ}$ and the inclination angle is $18.20^{\circ}-25.6^{\circ}$, with an average value of $21.90^{\circ}$. This value is close to the average angle of the rock slope, which is $24^{\circ}$ ( $\mathrm{Li}$ et al., 2005b). Because of the rapid development of cracks in No. 1 and No. 3 caves, the deformation and destruction of those caves is serious. At the same time, the observation and monitoring are more comprehensive, so the deformation and damage of cavern Nos. 1 and 3 (Fig. 2) are continuing to be analyzed. However, the author of current study assumes that investigating the crack mechanism of cavern No. 1 and 3 can provide a reference framework for analyzing the mechanism of vault cracks of other caverns, For

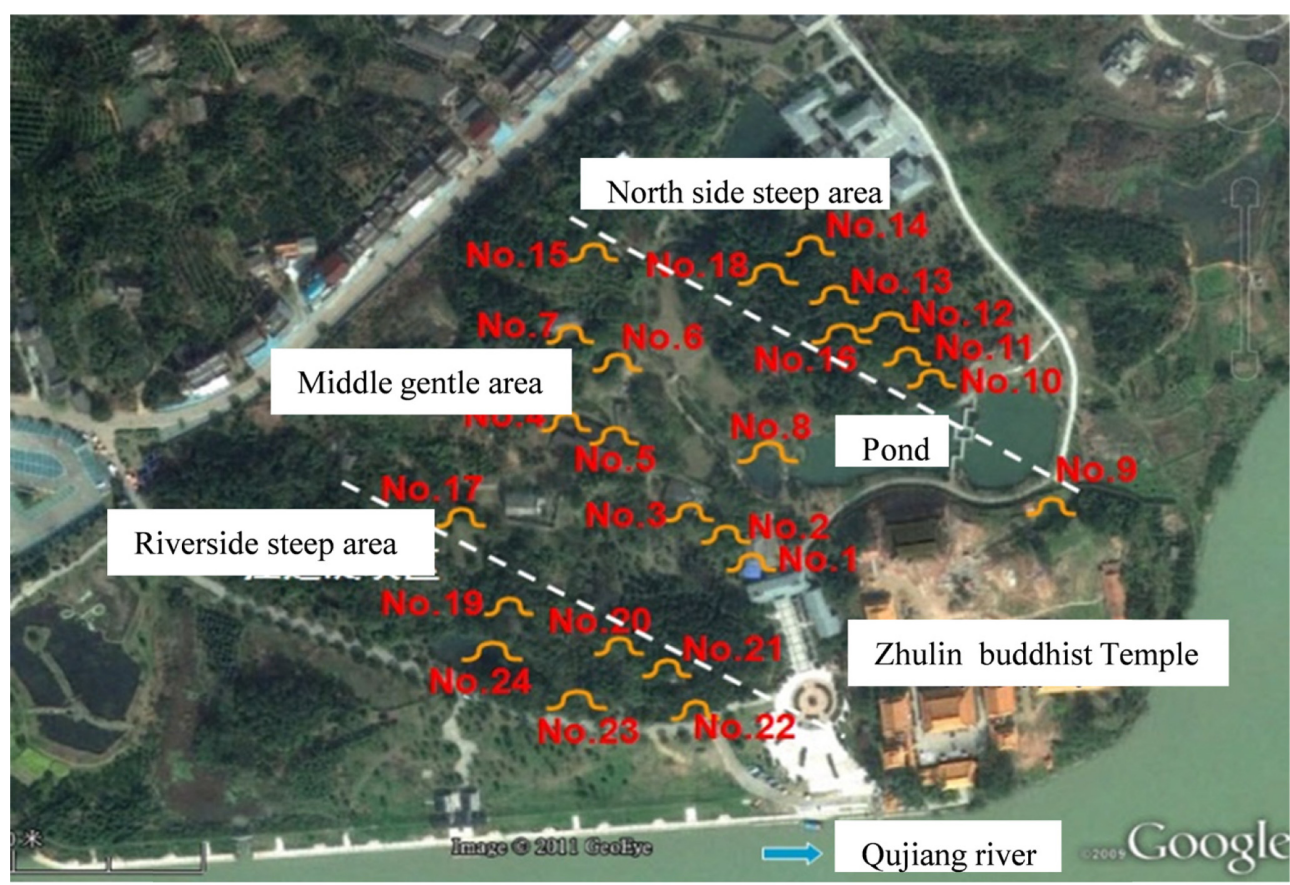

Figure 1. Distribution of ancient caverns atFenghuangMountain. 


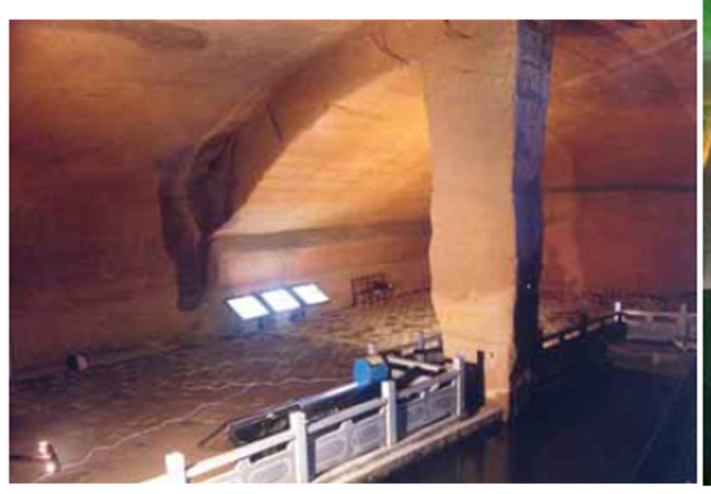

(a) No. 1

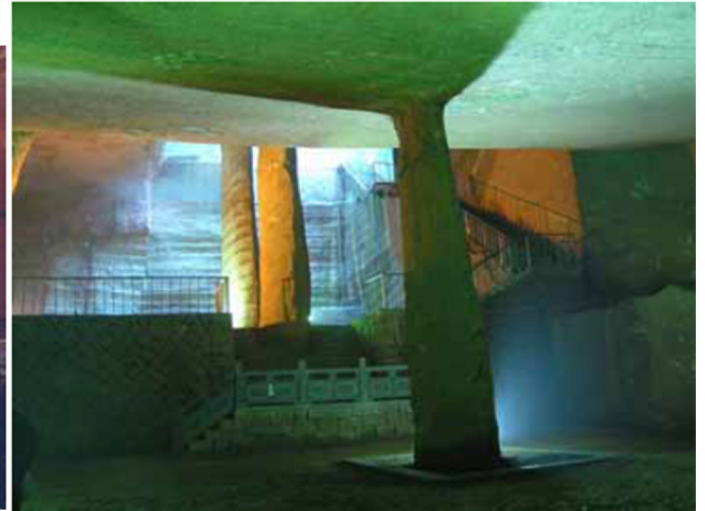

(b) No. 3

Figure 2. The global photograph of cavern No. 1 and No. 3.

example, the stress and environment of the vault at the entrance of No. 2 and No. 4 caves are very similar to those of No. 3 cave. At the same time, such an investigation will also contribute theoretical supporting values to the other project.

\section{History of Deformation and Destruction of the Vault in Ancient Caverns}

The vault between the 3-1 and 3-2 rock pillars in cavern No. 3, tensile cracks and arc cracks exhibited a trend that ranged from $0^{\circ}$ to $90^{\circ}$ (Wang et al., 2010). By comparatively analyzing the surveys and inspection records of cavern No. 3 (Fig. 3) in 2001, 2008, and 2017, it can be observed that the vault crack of cavern No. 3 are obviously continuously developing, especially due to an increase in the number of vault cracks around the upper part of the rock pillar. Additionally, the following points should be noted: (1) there is a partial separation on the northeast side of the vault of cavern No. 3 and (2) five new cracks were observed on the vault of the rock pillar 3-1 near the entrance in 2017. Similarly, new cracks also appear in other caverns, e.g., cavern No. 1. Fig. 4 shows a comparison of the expanding cracks in cavern No. 1 in 2001, 2008, 2009, and 2017.

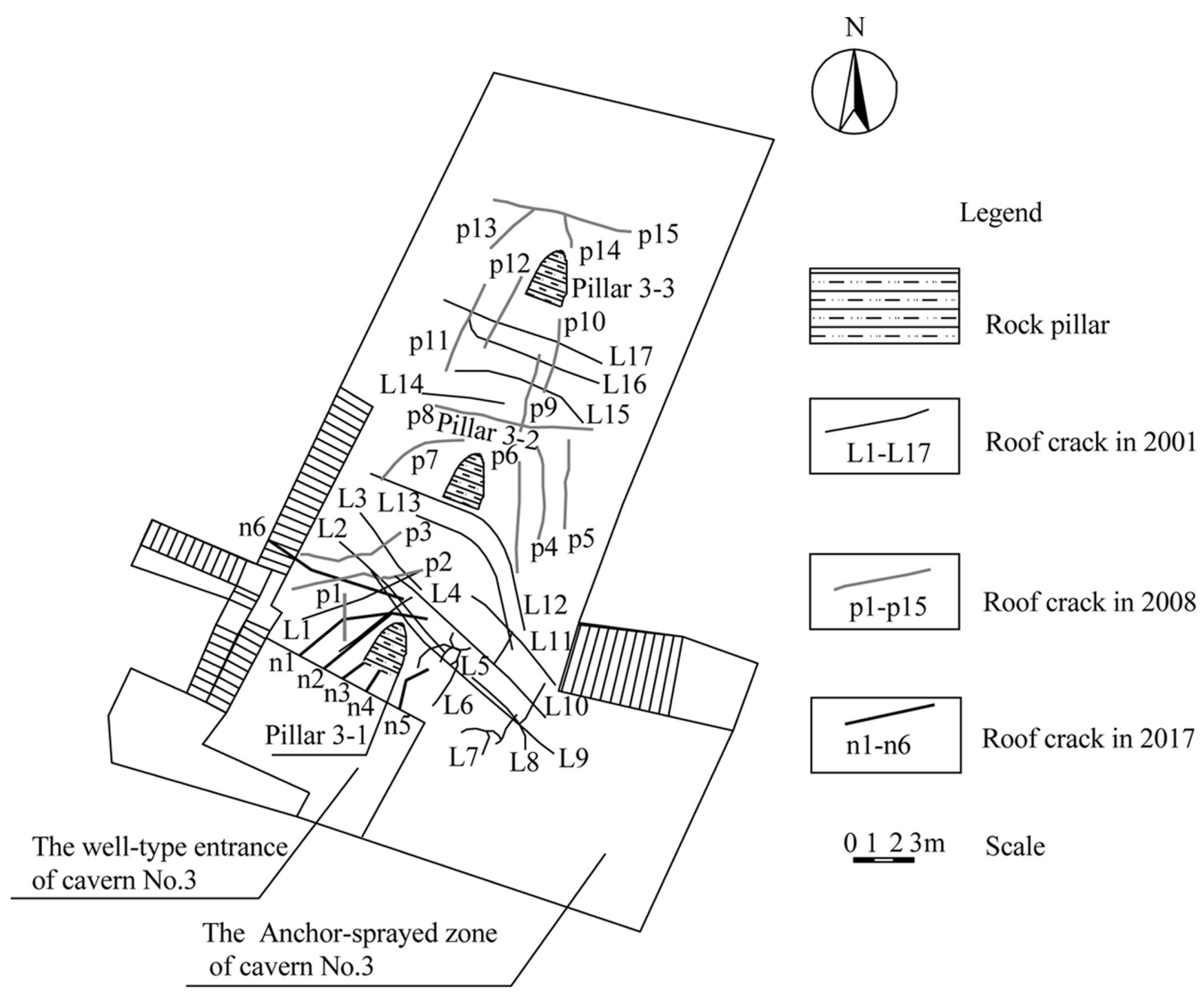

Figure 3. Cracks developed in cavern No. 3. 


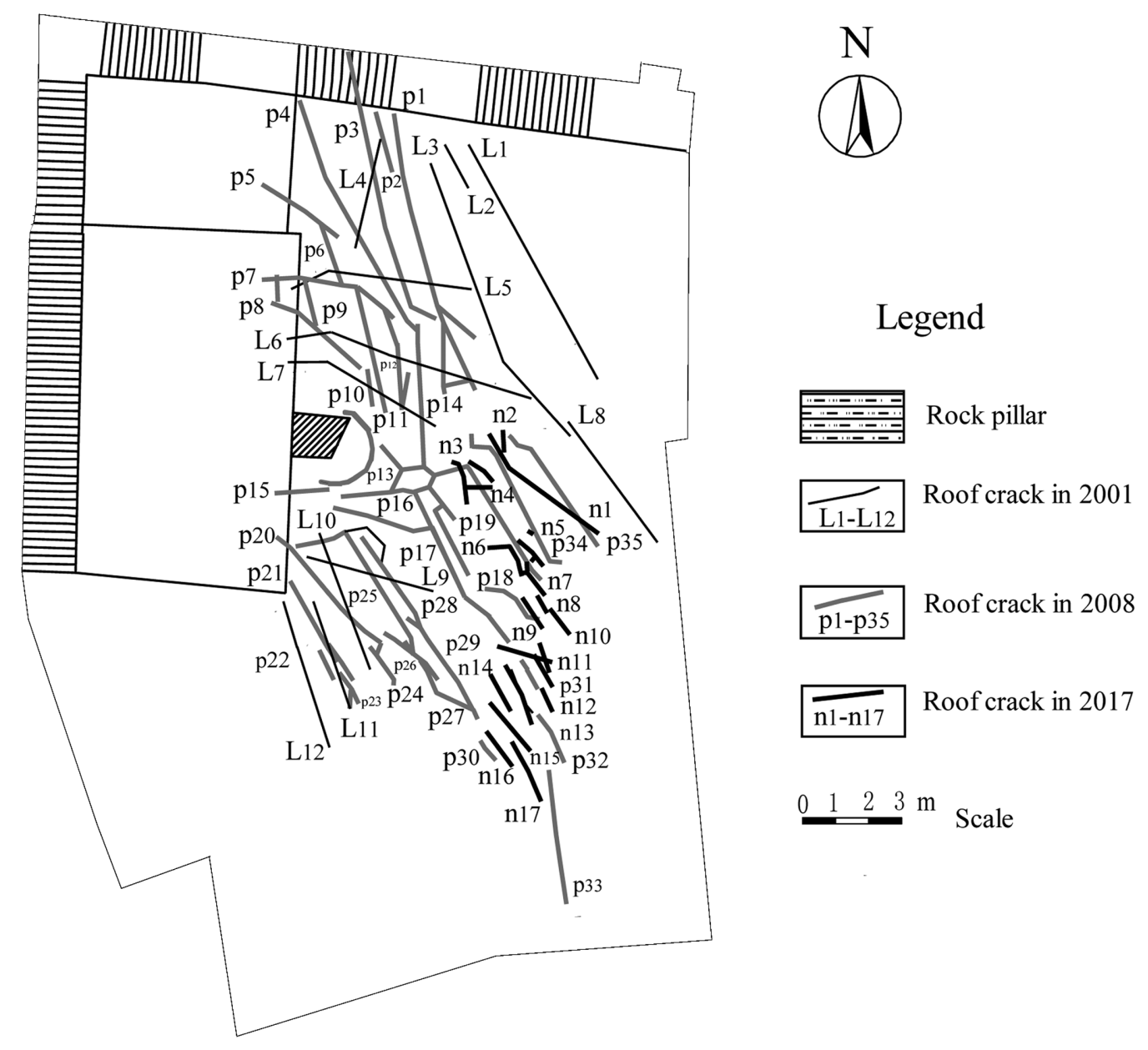

Figure 4. Cracks developed in cavern No. 1.

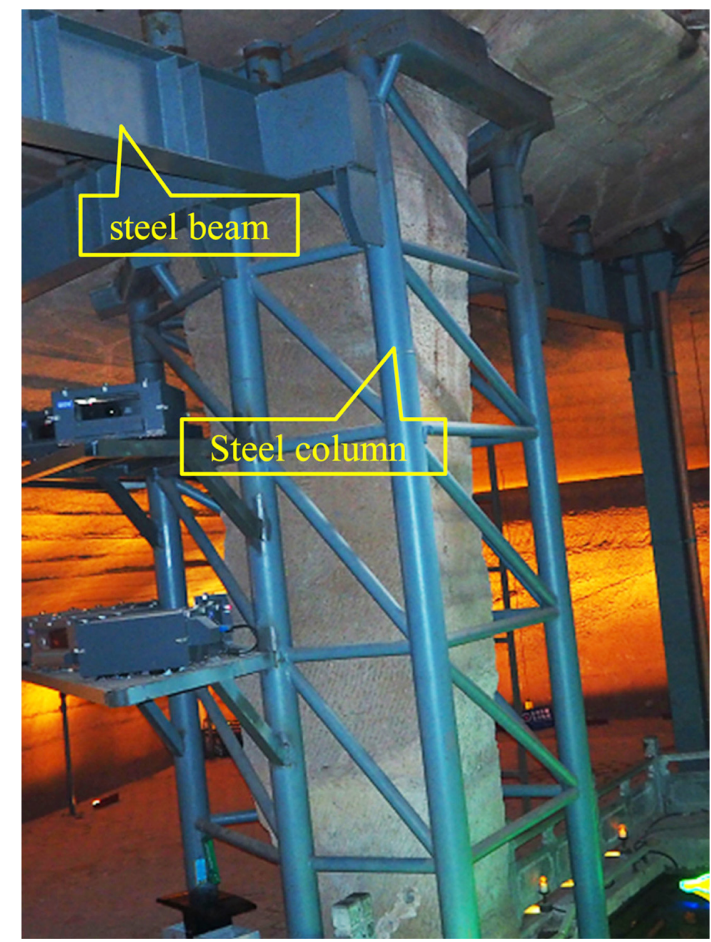

Figure 5. The preceding reinforcement chart of the 1-1 rock pillar in cavern No. 1.

\section{Adopted Reinforcement and Monitoring Measures}

To limit the further expansion of cracks, the scenic area management department used steel beams and columns to reinforce and support the vault near the rock pillar 1-1 of cavern No. 1 in 2007 (Fig. 5); the vault of rock pillar 3-1 in cavern No. 3 was reinforced with a combined steel column that comprised three reinforced steel columns (Fig. 6), and the changes in each column were observed. Additionally, a dial gauge coulometer was installed at key parts of the crack expansion points, e.g., at the top of the cavern and the side of the wall, to monitor the settlement and cracking conditions. Simultaneously, a thermometer and hygrometer were provided in each cavern to inspect and record the temperature and humidity, respectively, in the cavern. Thus, all of the aforementioned measures have been adopted to protect and monitor the deformation of the caverns in cavern Nos. 1 and 3.

\section{Factors Affecting Crack Expansion}

\section{Effect of the Top Rock Gravity at the Entrance}

The rock pillar 3-1 in cavern No. 3, which is the pillar near the entrance of the cavern, has an free surface at the top south portion of the pillar (the rock along the northern edge of the cavern). Addition- 


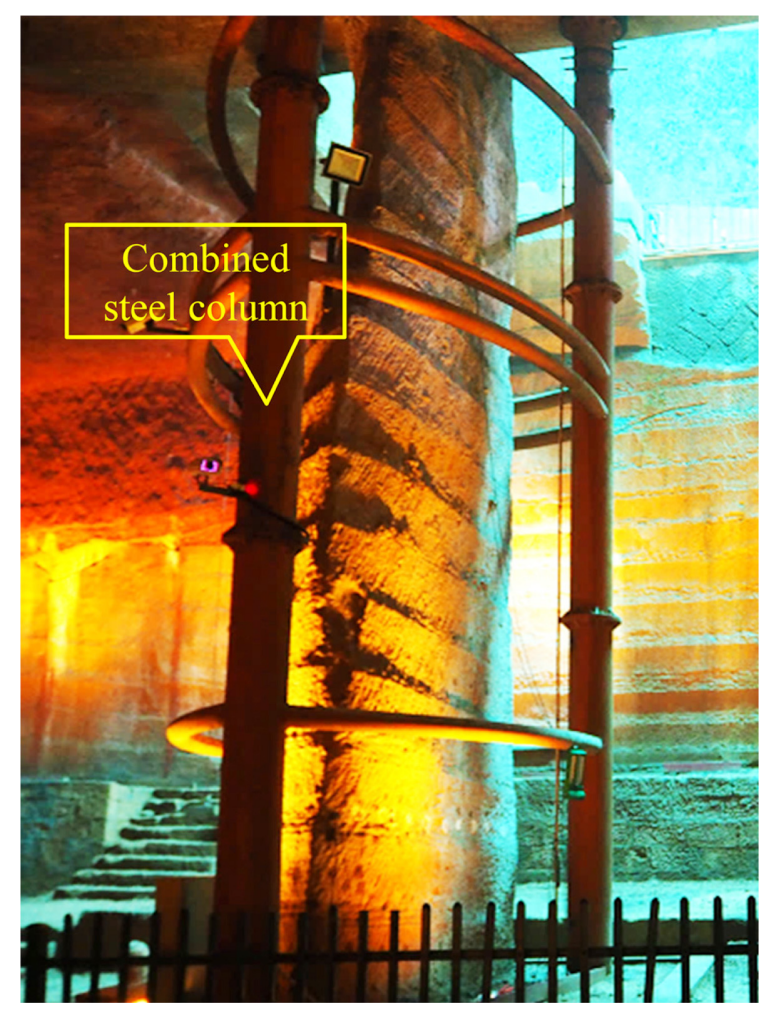

Figure 6. The preceding reinforcement chart of the 3-1 rock pillar in cavern No. 3.

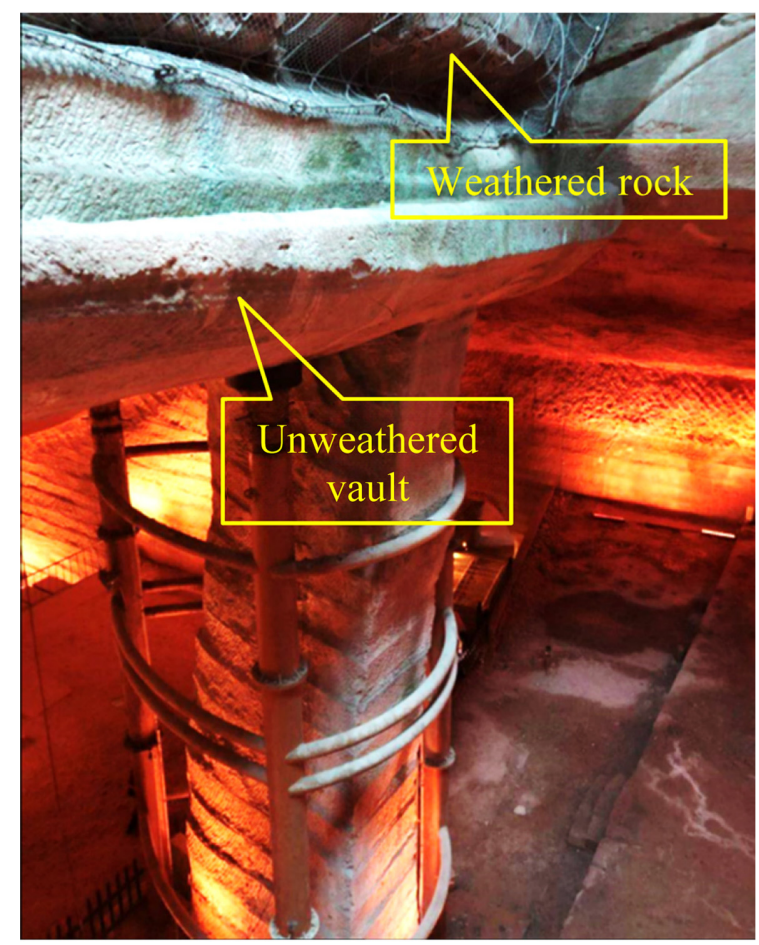

Figure 7. The entrance of cavern No. 3 and the 3-1 rock pillar on the north.

ally, there is a part of the vault that is suspended on the north side of the cavern. Furthermore, as shown in Figs. 8 and 9, there is a layer of rocks in the upper part of the cantilever at the cavern vault that has

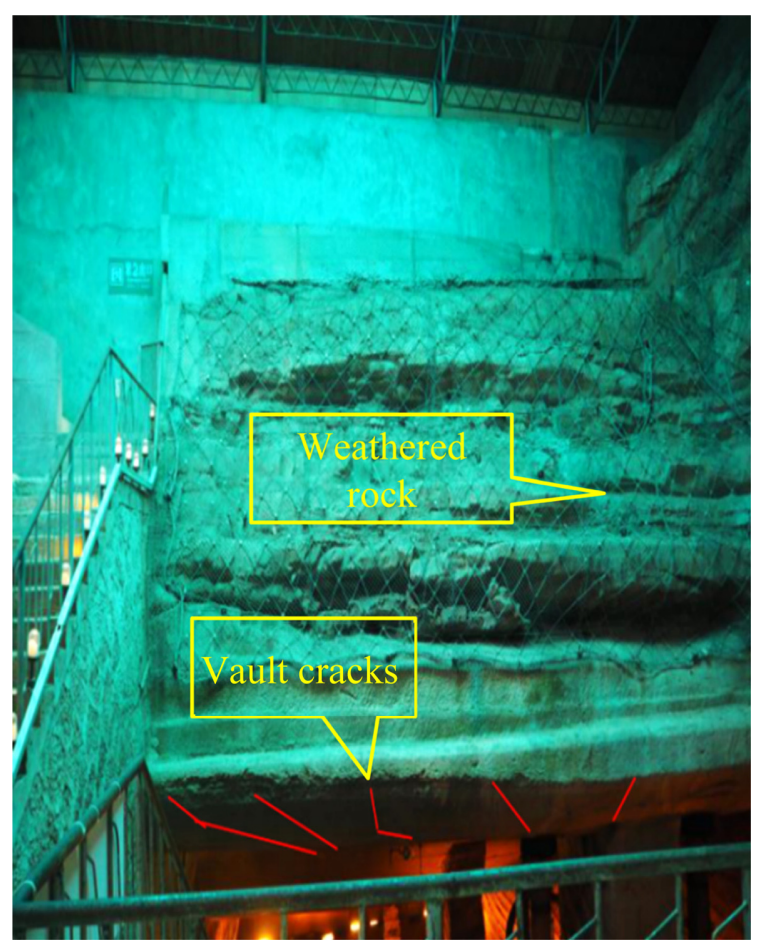

Figure 8. The rocks at the upper part of the entrance and the new cracks in cavern No. 3.

been formed as a result of weathering (Figs. 7 and 8). Further, the upper weathering rock, the artificial sheltered ceiling and the wall increase the pressure on the cavern vault (the whole load acts on the vault and the pillar 3-1, which causes the sinking of the vault). However, an investigation based on structural mechanics shows that the loads will be considerably increased in the curvature of the cantilevered part of the vault. Therefore, the rocks, the vault of the cavern, and the load on the wall are key factors for the development of cracks in the vault of the cavern.

\section{Effect of Free Surface at the Entrance}

The cantilevered vault of the cavern entrance (the north edge of the cavern) is observed to be thin (Fig. 9) which considerably influences the stability of the vault. At the free surface, the horizontal stress of the rock, which is perpendicular to the free surface, drops to zero and the stress tends to be well distributed for the surface away from the free surface (extending in the direction of the inner cavern). Because the west side of the entrance is bounded by the side wall and the east side has a continuous top plate, it exhibits the corresponding constraints. With the gradual extension into a cavern, both the east and west sides of the vault are constrained. Such an area that is indirectly constrained by both sides can be referred to as an "indirect constraint area," while an area that is directly constrained by the side wall and the vault can be referred to as a "direct constraint area." Generally, the stress in the directly constrained area is large, whereas that in the indirectly constrained area is small. Moreover, the rock in the indirectly constrained area can move toward the empty surface, whereas that in the empty surface is more likely to crack due to weathering. 


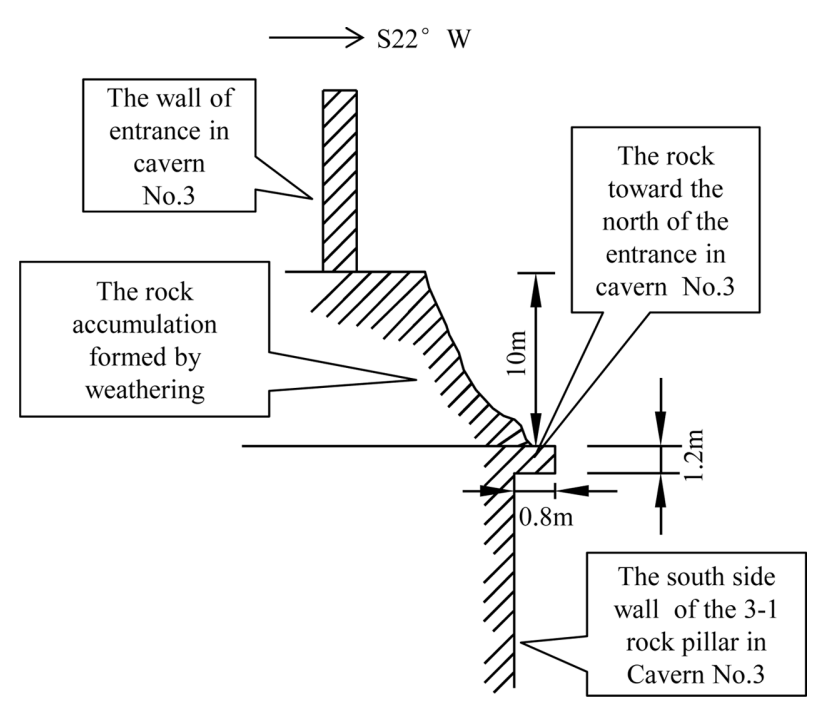

Figure 9. The 3-1 rock pillar in cavern No. 3 and the vertical profile toward the north of the entrance.

\section{Influence of Weathering with Multiple Factors, Includ- ing Sunlight, Air, Temperature, Human Activities, and Dry-Wet Cycles}

Due to the influence of various factors, including lighting and temperature, the rocks at the cavern entrance are weathered and the physical and chemical changes are observed. It is also necessary to mention the impact of rainwater. Acidic rainwater can chemically erode the rocks. However, rainwater alters the moisture content of the rock, which further affects the nature of the rock and varies the stress. Due to the thin overburden, the surface water invades the top of the cavern to a certain degree. The weathering of rocks is an important factor in crack generation, which is caused by the alternating wet and dry conditions of the wall rock of the cavern due to water seepage.

Additionally, groundwater influences the caverns. During the dry season, the groundwater level is higher than the surface water level; thus, the groundwater will flow into the rivers. However, during the wet season, the river water level is higher than the groundwater level; therefore, the river water will flow into the groundwater. This exhibits a corresponding impact on the wall rock of the cavern. Water seepage damage is caused due to the slow and periodic action of the weak seepage on the rock wall in different forms. Along with other weathering forces, the transition from quantity to quality leads to pollution, blurring, deformation, and destruction. The mechanism of this action is complex. Thus, the damage can be manifested based on the following aspects: softening the rock mass by wetting, weakening mechanical strength, mechanical and chemical latent corrosion, indirect destruction of seepage sediments, including crystalline erosion, decomposition erosion, and organic matter decomposition.

Furthermore, the air flow inside the caverns changes with the number of tourists, and human activities have a corresponding impact on the environment of the caverns, including the behaviors of the tourists, e.g., engraving on and touching the surrounding rocks. These factors together have a corresponding influence on the crack generation on the cavern vault, which must be considered while analyzing the treatment of the vault cracks.

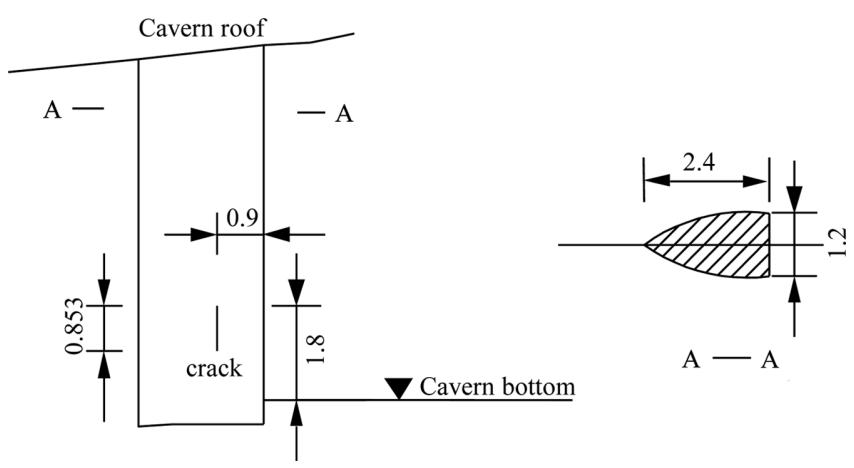

Figure 10. A vertical crack of approximately 0.853 meters long that appears on the 3-2 rock pillar (Unit: $m$ ).

\section{Influence of Rock Pillar Deformation on Vault Cracks}

The rock pillar 3-1 of cavern No. 3 is close to the entrance; therefore, it is subject to serious weathering due to various factors, which also reduces the strength of the rock pillar. Further, because the south side of the rock pillar is wide and the north side is narrow, rock pillar 3-1 is subjected to an uneven load of the vault, i.e., a biasing stress that acts on the rock pillar. Thus, the supporting strength of the rock pillar is considerably reduced and the vertical cracks are observed to occur. The original cracks in the vault have also expanded. Additionally, the rock column 3-2's deformation damage may cause changes in the monitoring data (Fig. 10), indicating that the strength of the rock column is decreasing. Decreasing stability of the rock pillar 3-2 will cause further cracking on the vault between the rock pillars 3-1 and 32. Therefore, the deformation of the rock pillar will result in vault crack expansion.

\section{Influence of Unloading on Vault Cracks}

Before the growth of tourism, the caverns were filled with water thus excluding air. The caverns were stable for thousands of years. However, after the growth of tourism, the water in the cavern has been drained and the vault and the wall of the caverns have become free surfaces that are exposed to air. The original stress balance of the whole cavern is broken, and stress redistribution has occurred. The strain direction is directed into the cavern. Cracks occur on the vault and walls of the cavern until a new stress balance is reached. The unloading stress cut the rock mass and produce various fractures, which is conducive to greater strength of weathering. At the same time, the cracks remain a main channel for water flows, which promotes the formation of water seepage damage.

\section{Analysis of the Vault Crack Expansion Mechanism of the Ancient Underground Cavern Introduction of the Fracture Types}

According to the application of an external force, fracture mechanics divides the cracks existing in a medium into three basic forms according to the form of crack propagation. (1) Open type (type I): the upper and lower surfaces displacements of the crack are symmetrical, the upper and lower surfaces of the crack are pulled 
apart due to the discontinuity of the normal displacement; (2) slipopen cracks (type II): under the action of a shear stress parallel to the crack surface and perpendicular to the crack front, the crack will slip-open and expand; (3) slitting cracks (type III): under the action of a shear stress parallel to both the crack surface and the crack front, the crack will tear and expand. Among these three basic fracture modes, type I crack is the most dangerous, which can easily cause brittle fractures. In the actual material structure, type I crack is the most likely observed to occur. However, the destruction of the material is often manifested in the form of complex cracking in actual conditions.

\section{Characteristics of the Cracks in Rock Masses and Their Fracture Types}

The main wall rock material of the ancient caverns is pelitic siltstone, which is a type of rock with medium hardness and is easily weathered. Additionally, the natural water content of the surrounding rock in each cavern is approximately $10 \%$. The physical and mechanical properties of the surrounding rock are listed in Tables 1 and 2 . Generally, the natural bulk density of sandstone ranges from 2.20 to 2.71 , the relative density ranges from 2.60 to 2.75 , the porosity ranges from $1.6 \%$ to $28.0 \%$, the softening coefficient ranges from 0.60 to 0.97 , and the Poisson's ratio ranges from 0.2 to 0.3 . From these two tables, it can be concluded that the diagenetic grade of the Cretaceous argillaceous siltstone is not high and that it exhibits medium-to-low water content and medium-to-low-density sandstone. According to its elastic modulus and uniaxial compressive strength, argillaceous siltstone is considered to be a rock with medium hardness (Yang et al., 2010). It can be observed from Fig. 2 that the rock of the vault at the surrounding area of the rock pillar in cavern No. 1 exhibits ring-shaped and semi-enclosed cracks (that is the ring-shaped crack near the column) and that the wall rock is weakly weathered in other areas at the top of the cave. The crack expands in the north-west direction with a steep dip angle. Groundwater seepage, leaching, and corrosion are simultaneously observed. The cracks in the vault near cavern No. 3 are also expanding (Fig. 1). There are 12 joint fractures on the east side of the cavern entrance. The length of the joint is increased to $9 \mathrm{~m}$, and there is groundwater seepage from the joints. Table 3 summarizes the statistics of the ring-shaped and semi-enclosed cracks, where $\mathrm{n} 1$ belongs to the type III crack category and the remaining ring-shaped and semi-enclosed cracks belong to the type I crack category. It is evident from Fig. 3 and Table 3 that there are several open cracks covering the north side of cavern No. 3 entrance and that the top plate of the pillar 3-1 is surrounded by ring-shaped and semi-enclosed cracks. Near the top plate of the entrance, there are slitting cracks at both ends of the empty surface with constraints. The remaining cracks at the top plate of cavern are mostly open cracks.

The rock parameters are measured based on the experimental data, and the critical value of the fracture can be deduced using the stress intensity factor, fracture toughness, and fracture basis ( $\mathrm{Lu}$ et al., 2014). The preliminary description of the theoretical basis for the expansion of fractures exhibits significance in terms of guidance for the actual project. Furthermore, the ancient caverns should be monitored in the long term so that the theoretical values can be compared with the actual values of the cracks to achieve improved theoretical results.

\section{Recommendations for Monitoring}

Real-time monitoring plays a crucial role in the overall stability of the ancient underground cavern of Longyou. The Longyou Grottoes Research Institute has employed a variety of instruments to monitor the cracking and sinking of the vault of ancient caverns from the end of 2008 to 2017.

Table 1. The basic physical properties of the surrounding rock of large ancient underground cavern group of Longyou

\begin{tabular}{ccccccc}
\hline \hline \multirow{2}{*}{ Test project } & Natural density & Dry density & Saturation density & Natural water content & Relative density & Porosity \\
\cline { 2 - 7 } & $\rho /\left(\mathrm{g} / \mathrm{cm}^{3}\right)$ & $\rho_{d} /\left(\mathrm{g} / \mathrm{cm}^{3}\right)$ & $\rho_{w} /\left(\mathrm{g} / \mathrm{cm}^{3}\right)$ & $\mathrm{w} / \%$ & $\mathrm{G}$ & $\mathrm{n} / \%$ \\
\hline Average & 2.28 & 2.21 & 2.31 & 4.31 & 2.71 & 19.19 \\
\hline
\end{tabular}

Table 2. The basic mechanical properties of the surrounding rock of large ancient underground cavern group of Longyou

\begin{tabular}{|c|c|c|c|c|c|c|c|}
\hline Water status & $\begin{array}{c}\text { Elastic modulus } \\
\mathrm{E} / \mathrm{MPa}\end{array}$ & $\begin{array}{c}\text { Poisson's ratio } \\
\mu\end{array}$ & $\begin{array}{c}\text { Uniaxial compressive } \\
\text { strength / MPa }\end{array}$ & $\begin{array}{c}\text { Softening } \\
\text { coefficient / \% }\end{array}$ & $\begin{array}{c}\text { Cohesive force } \\
\mathrm{c} / \mathrm{MPa}\end{array}$ & $\begin{array}{c}\text { Frictional angle } \\
\varphi /\left(^{\circ}\right)\end{array}$ & $\begin{array}{c}\text { Tensile strength } \\
\sigma_{t} / \mathrm{MPa}\end{array}$ \\
\hline Air drying & 4500 & 0.266 & 31.61 & \multirow{2}{*}{57.36} & & & \multirow[t]{2}{*}{1.63} \\
\hline Saturated water & 3030 & 0.269 & 18.13 & & 5.6 & 26 & \\
\hline
\end{tabular}

Table 3. The vault crack type classification of cavern No. 3 entrance

\begin{tabular}{cccc}
\hline \hline Crack type & Open type & Slitting Cracks & Ring-shaped and semi-enclosed cracks \\
\hline & $\mathrm{n} 2$ & $\mathrm{n} 5$ & $\mathrm{n} 1$ \\
& $\mathrm{n} 3$ & & L6 \\
Crack number & $\mathrm{n} 4$ & $\mathrm{~L} 7$ & $\mathrm{~L} 8$ \\
& $\mathrm{~L} 1$ & $\mathrm{P} 4$ & $\mathrm{P} 7$ \\
& $\mathrm{~L} 2$ & $\mathrm{P} 8$ & \\
\hline
\end{tabular}




\section{Crack Monitoring Examples}

The cracks on the top plate of ancient caverns are mainly monitored using a closed crack gauge because this type of instrument exhibits good performance in terms of moisture resistance. As an example, Fig. 11 shows the monitoring of a crack surface on the top plate of cavern No. 1. Additionally, Fig. 12 shows the distribution of the measurement points of cavern No. 3. The distribution points of the three gauges are presented as G3-R-C01, G3-R-C02, and G3-R-C03. Fig. 13 shows the annual average of the monitoring data for these three crack gauges for up to eight years.

The following conclusions can be obtained on analyzing Fig. 13. First, the three cracks are in the process of expansion. Among them, the cracking tendency of G3-R-C01 and G3-R-C02 was more obvious, whereas that of G3-R-C03 was relatively minor. Second, the slopes of the curves of G3-R-C01 and G3-R-C02 were larger before 2015, which indicates fast cracking speed, whereas the degrees of cracking at G3R-C02 and G3-R-C03 gradually decreased and tended to remain stable after 2015. Third, the curve of G3-R-C03 decreased before 2015; however, the crack width widened after 2015. Simultaneously, G3-R-

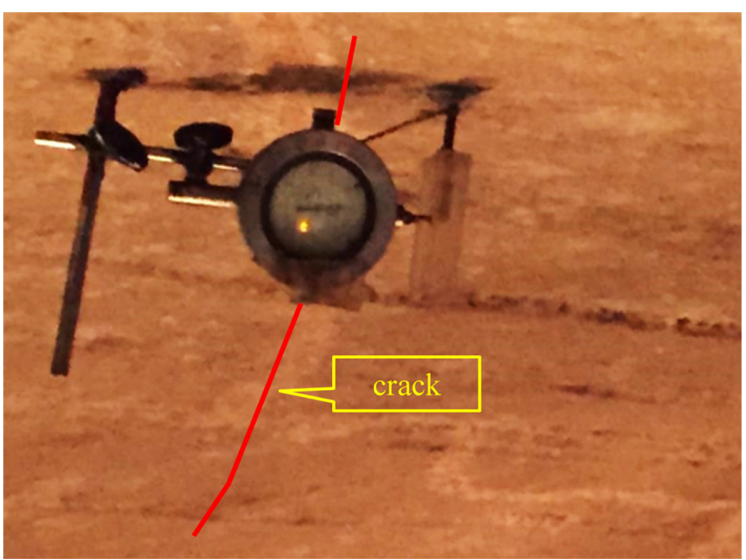

Figure 11. Monitoring the Vault of cavern No. 3 with a closed crack gauge (the gauge number is G3-R-C02).

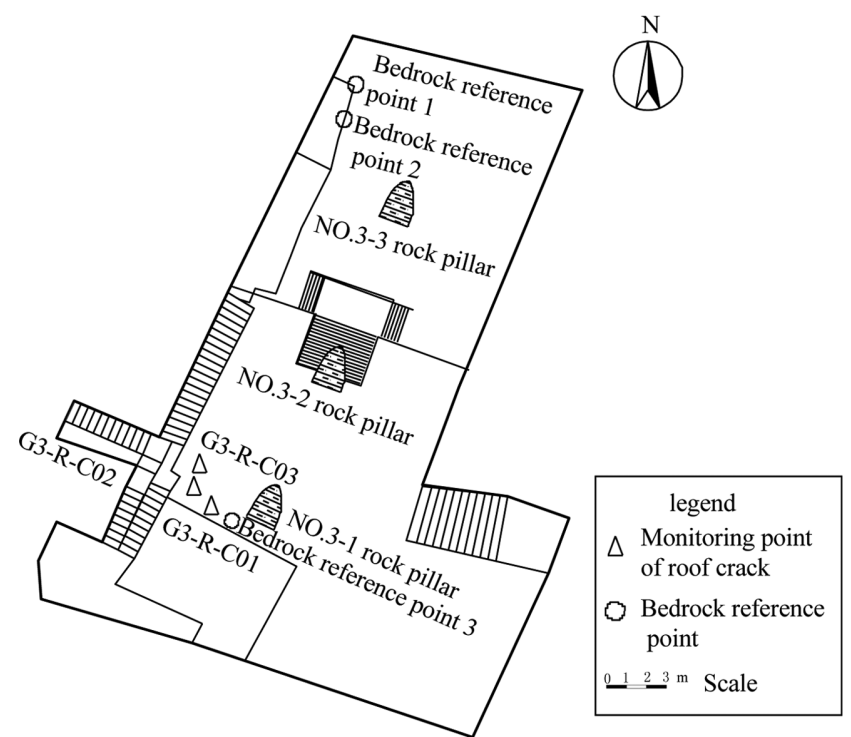

Figure 12. Distribution of the monitoring points of the closed crack gauge of the Vault in cavern No. 3.

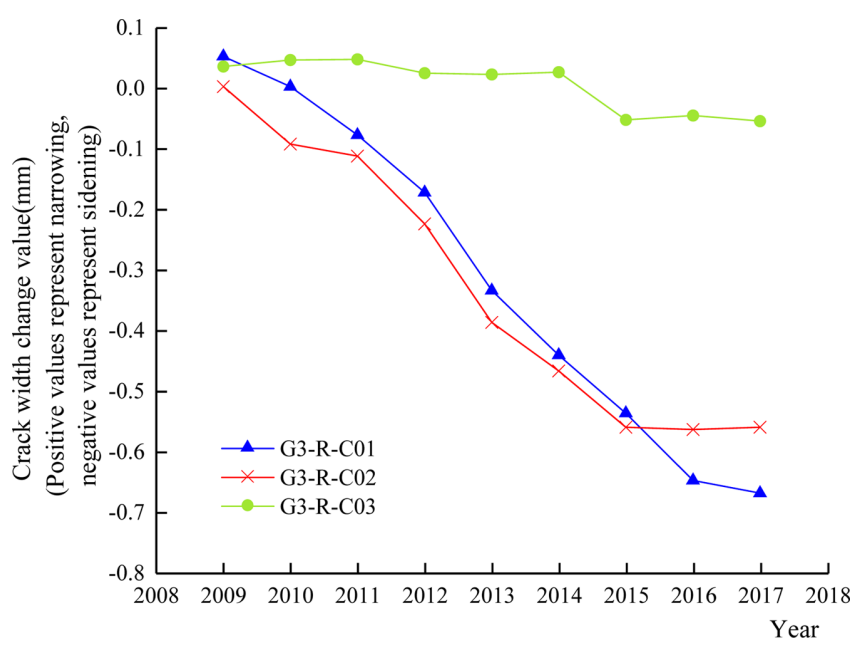

Figure 13. The change of vault cracking degree with time in cavern No. 3.

C01 exhibited the reverse phenomenon, i.e., it expanded before 2015 but decreased after 2015, which demonstrates that the top plate between G3-R-C01 and G3-R-C03 was constantly changing. Fourth, the cracking degree of G3-R-C01 decreased after 2016, but it does not tend to remain stable, which is consistent with the conclusion in Section 3 that the top plate at the free surface is unstable. Further, the crack of the vault near the free surface continued to expand due to multiple factors. Therefore, it is still necessary to reinforce and support the vault of the cavern entrance.

\section{Example of Settlement Monitoring}

Due to the good moisture-resistant performance of the settlement meter, with an oil-sealed dial indicator, this type of instrument is mainly used to monitor the vault settlement of the ancient caverns (Fig. 14).

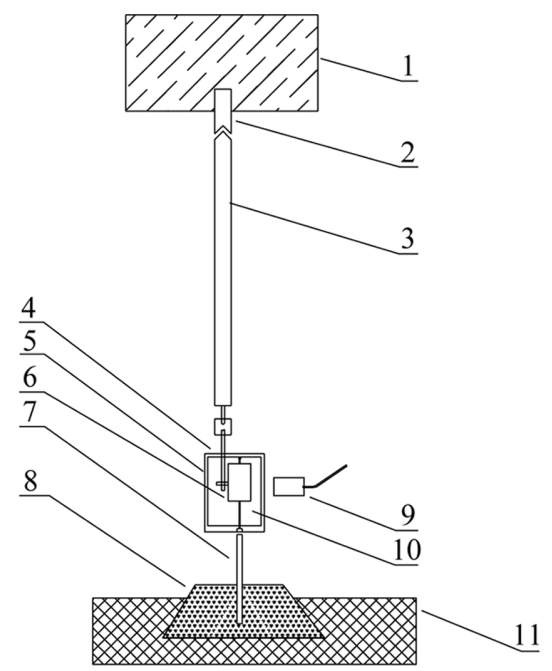

1.Cavern roof; 2.Hanging embedded parts; 3.Dowel bar; 4.Perforated cover plate; 5.Test tube; 6 .Dial indicator; 7.Cavern bottom embedded parts; 8.Concrete pier; 9.Image acquisition device; 10.Kerosene;

11. Cavern bottom

Figure 14. Schematic of the installation structure of the settlement meter with oil sealing and dial indicator. 


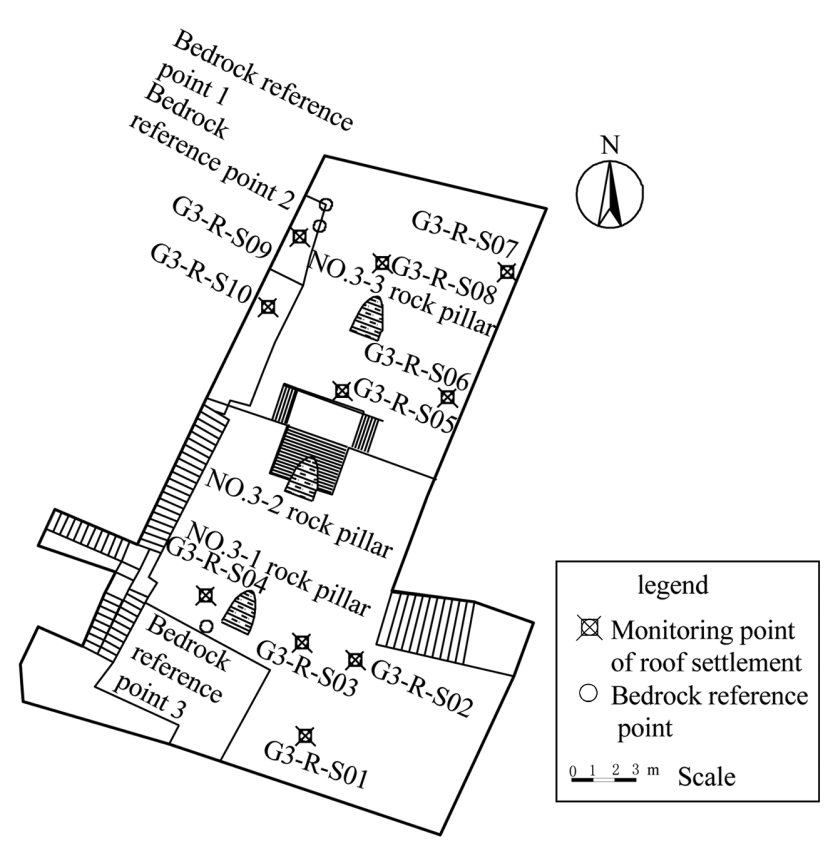

Figure 15. Distribution of the monitoring points in cavern No. 3.

Fig. 15 shows the position of the measuring points that are installed on the top plate of cavern No. 3 .

The following conclusions can be obtained on analyzing Fig. 16. First, the settlement values at G3-R-S03 and G3-R-S04 tended to remain stable, whereas those of the other three underwent constant changes. Among them, the top plate settlement value at G3-R-S05 continued to increase and there was no tendency of achieving stabilization. Therefore, it is necessary to support the vault near the rock pillar 3-2. Second, the analysis that combines the settlement values of the monitoring points (Fig. 16) and the distribution positions of the points (Fig. 15) observed that G3-R-S01 and G3-R-S02 exhibit opposite trends and G3-R-S03 and G3-R-S04 exhibit opposite trends. This shows that the settlement of the top plate is performed in separate blocks and that the settlement of each block occurs via pressing from the adjacent block that causes it to sink on one side and rise at another,

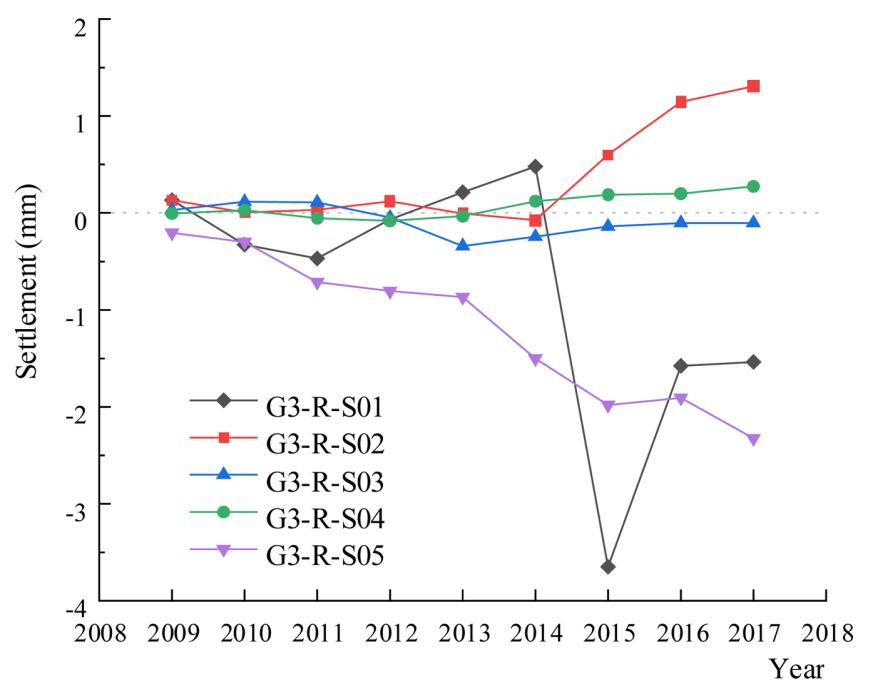

Figure 16. The change of vault settlement with time in cavern No. 3. which demonstrates an uneven settlement of the top plate. Third, the settlement at G3-R-S01 changed significantly, and it suddenly sank in 2015. However, G3-R-S02 was found to have upturned and G3-RS01 and G3-R-S02 experienced relatively common movements. After 2015, it gradually decreased. It was concluded that weathering and erosion appeared on the surface of the anchor spray zone under the conditions of temperature, humidity and biological weathering after which the weathering became uniform. Therefore, the monitoring value tended to become stable again.

\section{Suggestions for Reinforcement}

\section{Reinforcement Solution}

According to the analysis of the aforementioned interpretations and the monitoring data, it removal of the layers of rock that are heavily weathered on the north part of cavern No. 3 is recommended (Fig. 9) in a few steps to avoid sudden stress release generated due to unloading which would damage the top plate again. This can improve the strength problems of the rock pillar under the support of the combined steel column. However, the vault has already generated ringed cracks, the fractures are completely expanding, the vault is in an incomplete state (Fig. 3), and the vault will be pierced as a result of continuous crack expansion. Therefore, it is recommended that the cave should be reinforced as a whole. Fig. 17(a) depicts the layout of the reinforcement scheme. This scheme intends to arrange the steel columns in the key parts of the cavern and set the steel beams in the corresponding positions (Fig. 17(b), such as the edge of the empty surface or at the top plate of the cavern). This reinforcement scheme not only conforms in principle to the National Cultural Relics Protection Law that does not change the original appearance of the cultural relics as much as possible but also effectively protects the overall stability of the cavern (Adopted by the Thirtieth session of the Standing Committee of the Ninth National People's Congress 2002), which will makes this wonder of ancient human culture enjoyable in future.

\section{Visualization of 3D Reinforcement}

Based on the analysis of the overall conditions of the cavern (including the deformation and damage conditions), Fig. 17 depicts the reinforcement design for cavern No. 3. Assuming that more people can understand and participate in the protection of the caverns, it is recommended that BIM technology is applied to the $3 \mathrm{D}$ display of the reinforcement of the caverns. Therefore, it is necessary to establish a 3D geological model and a 3D reinforcement model and to display the actual situation of the ancient underground cavern of Longyou in an all-round way so as to secure life cycle information management of the Longyou Grottoes as the building construction process (Xu et al., 2014).

\section{Application of BIMTechnology in Geotechnical Engineering}

There are two commonly used methods for implementing 3D geological modeling in the existing BIM platform (Huang et al., 2016). The first one is to use the Civil 3D surface modeling method to manu- 


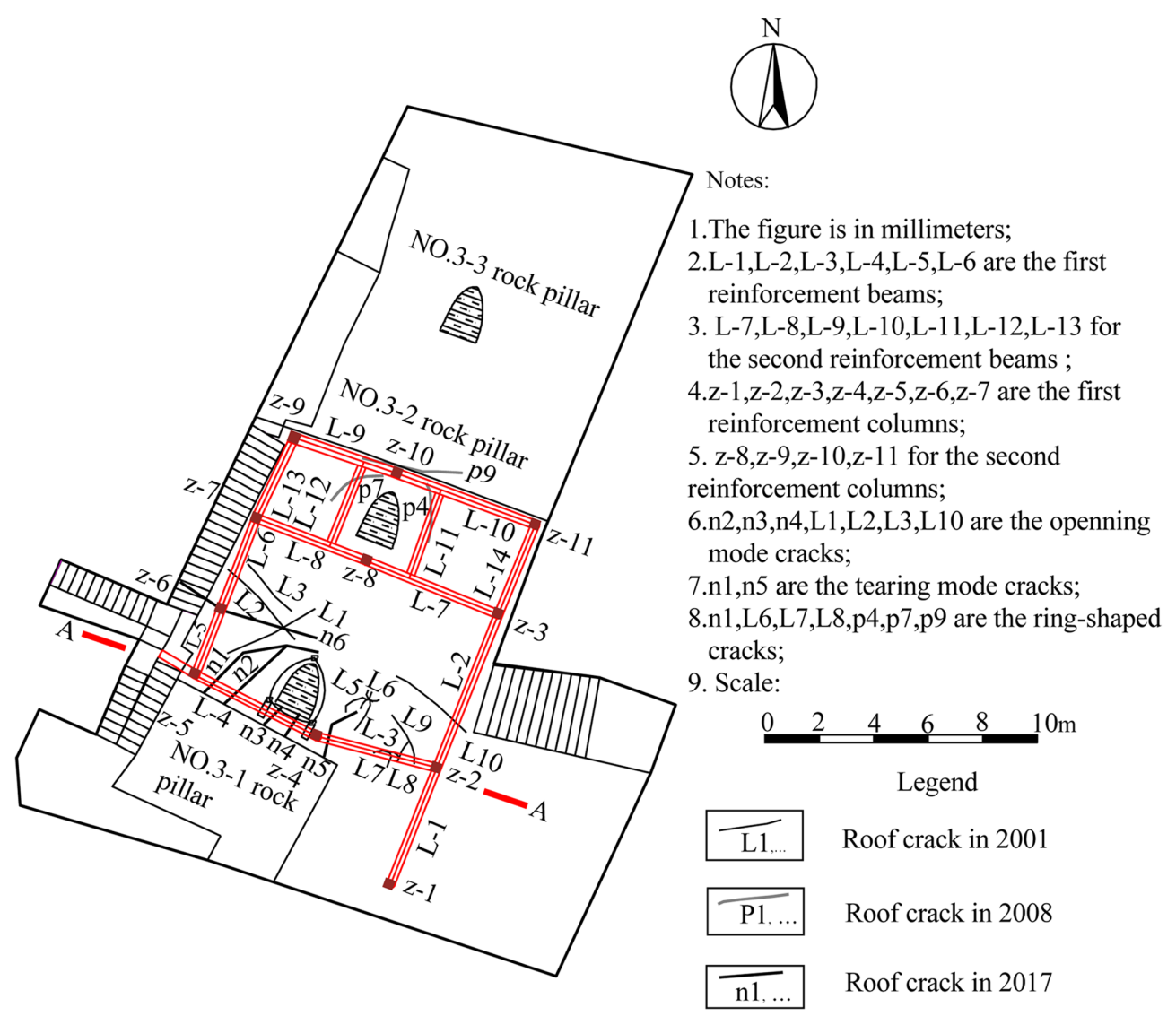

(a) General reinforcement layout

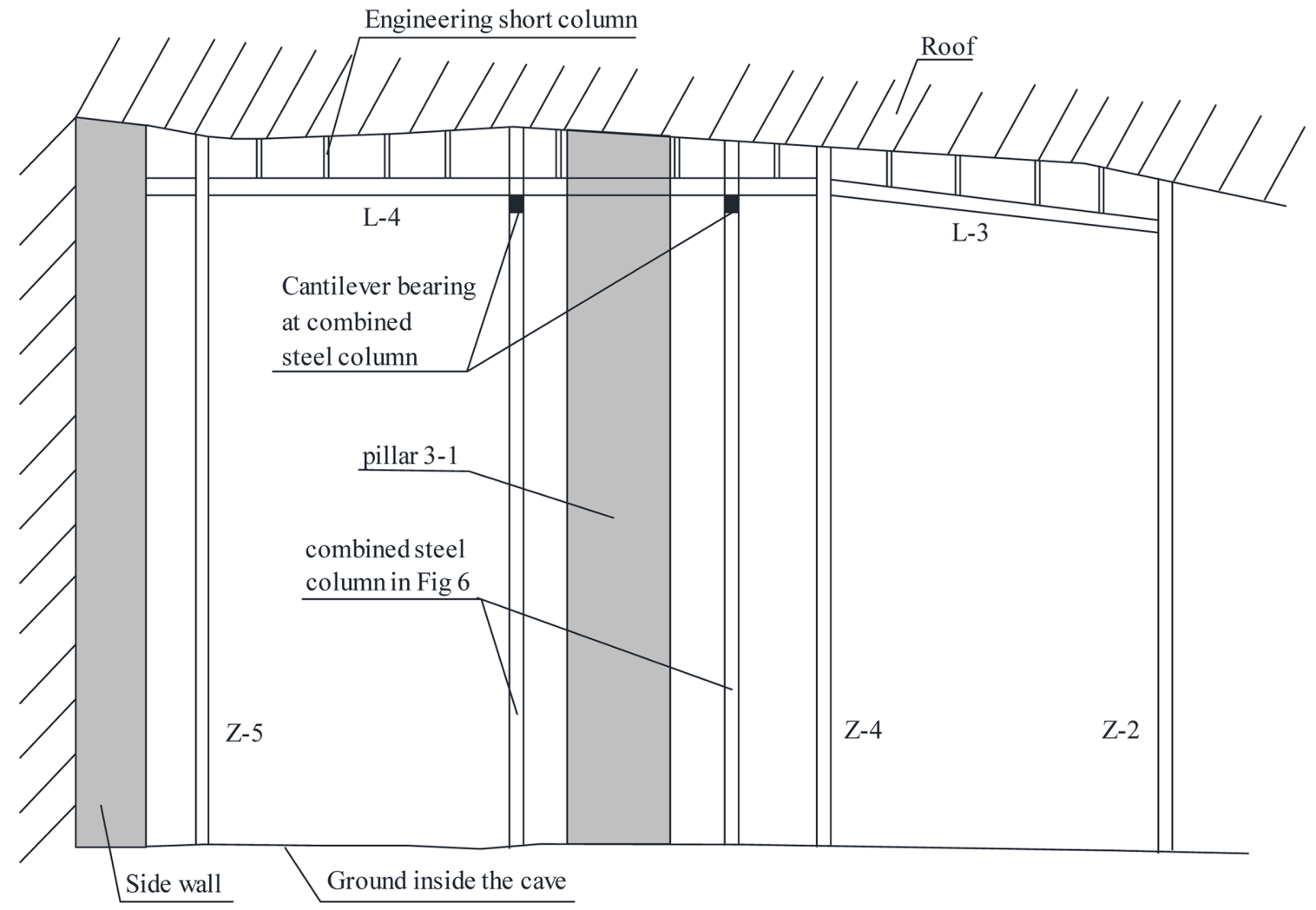

(b) A-A Section

Figure 17. Reinforcement of cavern No. 3. 
ally create or import data to establish the upper and lower surfaces of the soil layer and further form soil units by generating the solids through the upper and lower surfaces. The second one is to use the plate element in Revit software for modifying a material to simulate the soil unit. The different elevations of the surface level can be modified by revising the sub-elements. The reinforcement support model can also be quickly established using Revit software. The support member can be built by the actual size through the function of Revit. The 3D geological model and support model can be integrated to form a complete 3D visualization space using different modeling methods to solve the practical problems (Maxelon et al., 2009).

After the model is established, it can be imported into the Navisworks software to verify the accuracy of the model. Further, the problematic components can be screened to ensure that the established model is free from conflicts, omissions, and imperfections. After modifying the model, it can be further imported into Lumion software, which has a realistic material simulation function. It can achieve the highest degree of the simulation effect by replacing the less accurately represented material with a material that is closest to the actual material. At the same time, it can also output realistic renderings in videos and pictures to provide researchers with intuitive visual research data.

\section{Difficulties in Applying the BIM Technology in Geotechni- cal Engineering}

Currently, the BIM technology is extensively used in the field of building structures and its application in geotechnical field is still limited. It should be noted that the BIM technology is applied earlier in the building structure and that the software's second stage development has improved; however, in the geotechnical field, the BIM technology is in its infancy (Zhang et al., 2016). The development of the BIM technology is relatively complete in the field of building structures and the software has already established a corresponding component library system. However, to date, geotechnical engineering has not yet developed a parameterized family library system that is useful. This is because of the different characteristics of the two projects. Geotechnical engineering modeling exhibits large irregularities and low reusability, whereas the building structure components are more regular. Further, a parameterized family library can be built once and the size parameters can be modified during later use. For example, the Revit family library assigns a large number of Revit primitives with attributes and parameters and classifies and archives them in the form of a database. However, in geotechnical engineering, the reusability of this system is relatively low, which leads to slow development of the geotechnical BIM technology. Therefore, to promote the application of the BIM technology in geotechnical engineering, further research is necessary.

\section{Application of the BIM Technology to the Ancient Under- ground Project of Longyou}

The Longyou Grottoes described in this study are planned to be modeled using the Revit software by performing the following steps. First, a 3D geological model of the caverns will be established so that all the caverns can be completely displayed to provide a reinforcement platform for the support model. Second, based on the established geo- logical model, a reinforcement model will be set up at the corresponding coordinate and elevation position according to the designed reinforcement scheme.

\section{(1) Establishment of a 3D geological model}

While establishing a 3D geological model of the Longyou Grottoes, it was noted that the ancient caverns in Longyou exhibited the following characteristics: the rock mass comprised brick-red argillaceous siltstone; the top surface of the cavern was a curved surface, and the surrounding walls were inclined; the cross section of the rock column had an iron-like shape; the wall rocks were carved with fine texture; and the bottom of the cavern comprised different elevation steps. Certainly, the irregularities, multiple elevations, fine carved marks, and inclined walls all caused difficulties in modeling. Therefore, to address these issues, some suggestions are provided. Separate family establishment should be adopted for the pillars and other special-shaped surface components. The volume method should be used to solve the curved surface problem. The problem of multiple elevations can be resolved using the original elevation input to avoid any disorder. It is very difficult to display the fine carved marks in a large space environment; therefore, the author adopts the solution of importing the model into Lumion after it has been established. If the volume method is used to resolve the problem of the inclined wall, there will be a large difference in case of the actual condition. A difference is observed in both the longitudinal and lateral directions as well as in the inner and outer portions of the rock wall; hence, it is not appropriate to use the volume method. The method of changing the elevation of sub-elements in the plate element was used to establish the inclined rock wall, i.e., to change the elevation according to different protrusions both inside and outside the rock wall to make it more realistic (Fig. 18). Because these problems have been resolved, an improved $3 \mathrm{D}$ geological model can be established.

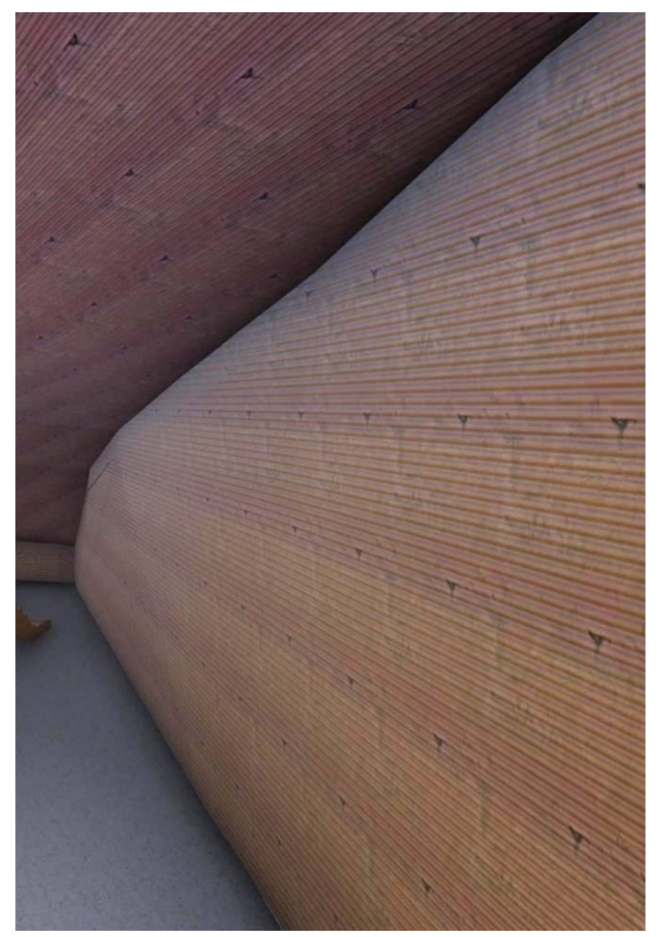

Figure 18. 3D visualization of the inclined wall and the vault. 
(2) Establishment of a reinforcement support model

After establishing a 3D geological model, it should be imported into Navisworks to verify the existing problems of the model and rectify them in time. According to the reinforcement scheme depicted in Fig. 17 and based on the real size, a support model is built on the basis of a 3D geological model. However, for the small support at the top of the beam (Fig. 19) and the polygon beam, it is still necessary to establish a separate family to build these models. Additionally, collision detection is one of the most extensively used functions in the BIM platform. This module can verify the feasibility of our design scheme and reduce the cost involved in rectifying the design errors. This function can also be used in geotechnical engineering (Yang, 2005) to perform collision detection between column top, a small support on the beam top and the cavern top, the column base and the ground rock. Using collision detection, the depth of the support body inserted into the wall rock can be detected and the length of the column can be adjusted according to the collision result, which can reduce the project cost (as depicted in Fig. 20).

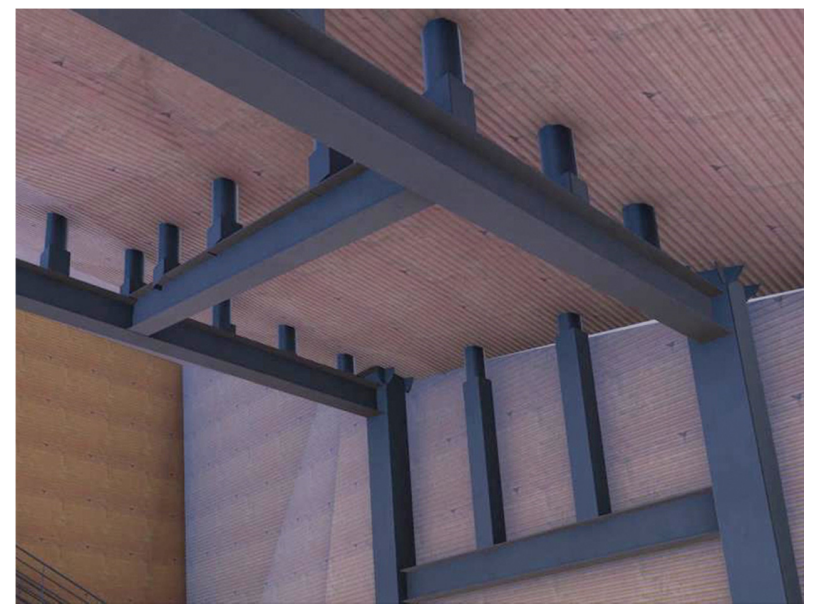

Figure 19. Visualization of the engineering short column between the beam top and the vault top.

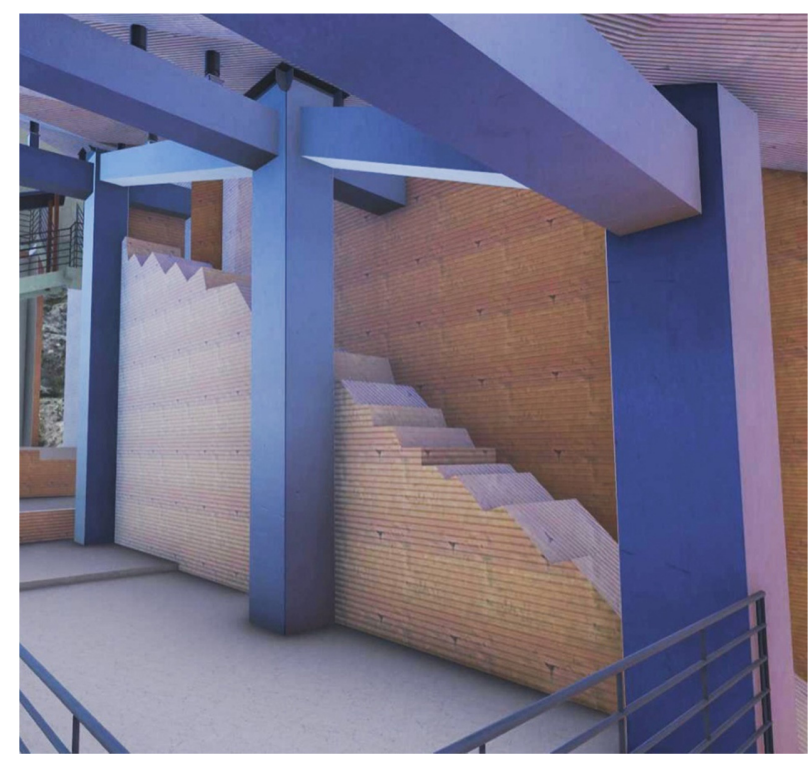

Figure 20. Reinforcement visualization of steel column and steel beam.
After solving the aforementioned problems, a complete 3D geological model and support model can be obtained to provide intuitive information for subsequent research. It will play an important role in protecting the ancient underground project. Additionally, it will serve as a guidance material for the subsequent construction process. The resulting reduction of the construction cost and the guidance during the construction project using BIM technology will have major significance for the ancient underground project of Longyou. Furthermore, for a method that resolves the aforementioned problems, the specific families involved in geotechnical engineering can be collected as shared data to promote step-by-step application of the BIM technology in geotechnical engineering more generally.

\section{Conclusions}

After comprehensively analyzing the vaults of cavern Nos. 1 and 3 using multiple factors, theories, and long-term monitoring, the following conclusions were obtained.

(1) In this study, the factors affecting the expansion of cracks and the characteristics of cracks under the influence of multiple factors must be analyzed. Further, the influence of these factors on the cracks of the top plate must be comprehensively analyzed. Through followup monitoring and inspection, the proportion of various factors affecting crack generation on the vault can be studied. (2) By employing the theory of rock mechanics and fracture mechanics to analyze the mechanism of cracks on the vault of cavern No. 3, the regular pattern of crack expansion could be better studied by combining theoretical analysis and onsite monitoring. At the same time, it provides significant insights related to the study about crack expansion on the vaults of other caverns. In addition, it is recommended to adopt the reinforcement scheme mentioned herein. (3) The objectives of the proposed introduction of BIM technology to investigate the ancient underground project of Longyou are as follows: 1) it introduces new ideas and 3D data to perform research and ensure protection of the underground project, 2) it can reduce the reinforcement cost and provide guidance for subsequent construction, and 3) it will plays an important role in developing the application of the BIM technology to geotechnical projects more generally.

\section{Acknowledgement}

The research received funding from the National Natural Science Foundation of China (41672321) and Special research project of Shaanxi Provincial Education Department (16JK1489).

\section{References}

Adopted by the Thirtieth session of the Standing Committee of the Ninth National People's Congress. The announcement of the No. Seventy-six Presidential Decree, 2002, Law of the Peoples Republic of China on Protection of Cultural Relics, 5p.

Gregory, M., Christopher, M., and Debasis, D., 2001, Using the coal mine vault rating (CMRR) to assess vault stability in U.S. coal mines. Mining industry annual review. Journal of Mines, Metals and Fuels, v. 15, 
pp. 314-321.

Huang, K.Z., 2006, A new member of grottos-Longyou grottos. Proceedings of International Symposium on Protection of Longyou Grottos in China, 2006, Culture Relics Publish House: 388-392.

Huang, J.M., Zheng, X.C., Hou, J., He, B., and Liu, Y., 2016, Research on Application of BIM technology in geotechnical engineering. Urban Reconnaissance, v. 02, pp. 157-160.

Li, L.H., Yang, Z.F., Yue, Z.Q., Pan, W., and Mou, H.C., 2005a, Deformation and failure modes and reinforcement methods of ancient cavern group in Longyou county. Chinese Journal of Rock Mechanics and Engineering, v. 242, pp. 2018-2028.

Li, L.H., Yang, Z.F., Zhang, L.Q., Qi, S.W., Lu, M., and Zheng, J., 2005b, On the engineering scientific problems about the inclined vault design of Longyou grottoes. Chinese Journal of Rock Mechanics and Engineering, v. 24, pp. 336-343.

Lu, Z.D., Chen, C.X., Feng, X.T., and Zhang, Y.L., 2014, Strength failure and crack coalescence behavior of sandstone containing single pre-cut fissure under coupled stress, fluid flow and changing chemical environment. Journal of Central South University, v. 3, pp. 1176-1183.

Maxelon, M., Renard, P., Courrioux, G., Brändli, M., and Mancktelow, N., 2009, A workflow to facilitate three-dimensional geometrical modeling of complex poly-deformed geological units. Computers \& Geosciences, v. 3, pp. 644-658.

Tanimoto, C., 2006, Concluding remarks from Prof. Tamimoto Osakalluversi. Proceedings of the International Symposium on Protection of Longyou Grottoes in China, 2006, Beijing: Culture Relics Publishing House: 11-12.

Wang, S.J., 2001, The wonderful artificial excelling nature, Longyong Grottoes. Rock Mechanics and Engineering Trends, v. 53, pp. 8-9.

Wang, X.L., Zhang, L.Q., Zhang, Z.J., Fu, Y., Liu, E.C., and Gao, Q., 2010, Influence of deformation and failure of 3-2 rock pillar on the stress variation of No. 3 tunnel in Longyou Grottoes. Geotechnical Engineering, v. 12, pp. 3919-3927.

Xu, X., Ma, L., and Ding, L.Y., 2014, A framework for BIM-enabled lifecycle information management of construction project. International Journal of Advanced Robotic Systems, v. 11, pp. 126-134.

Yang, Z.F., Wang, S.J., Xu, B., Zhan, Y.P., Xu, J.H., Guo, J.J., and Zhang, Q., 2000, Analysis of the engineering geological conditions of Longyou stone caverns and primary study on the protection strategies. Journal of Engineering Geology, v. 8, pp. 291-295.

Yang, Z.F., Li, L.H., Pan, W., Lu M., and Zheng, J., 2003, Discussions about large-scale ancient underground engineering. Science Technology and Engineering, v. 3, pp. 23-27.

Yang, L.D., 2005, A study on the values and protection of Longyou grottos. Chinese Journal of Underground Space and Engineering, v. 1, pp. $11-14$.

Yang, Z.F., Yue, Z.Q., and Li, L.H., 2010, Research on Science and Technology problems of large underground engineering caverns in Longyou Grottoes. Science Press, Beijing, 126p.
Zhang, J.Q., Wu, C.L., Wang, L.Z., Mao X.P., and Wu, Y., 2016, The Work flow and operational model for geotechnical investigation based on BIM. IEEE Access, v. 14, pp. 7500-7508.

Zhu, J.W., Chang, Z.H., Liu, E.C., Zhang L.Q., and Yang, Z.F., 2009, Study on the causes and reinforcement measures for the destruction of No. 1 cave in Longyou Grottoes. Journal of Engineering Geology, v. 17, pp. 126-133.

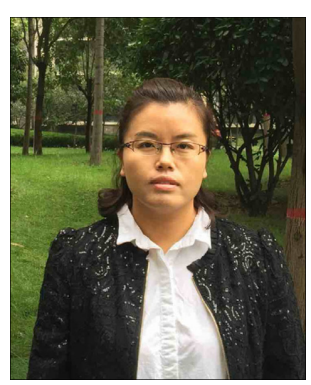

Bingli Gao, She is a National Registered Civil (Geotechnical) Engineer, and she is a director of the 7th Shaanxi Society of Geotechnical Mechanics and Engineering. She is mainly engaged in geotechnical engineering, slope engineering, ancient engineering, disaster prevention and mitigation engineering etc. More than 20 papers have been published by her as the first author, and 1 monograph, 2 teaching materials, 2 local standards of Shaanxi province engineering construction, 3 practical new patents and 1 software copyright have been done; she is in charge of projects on underground engineering, slope engineering and ancient engineering for long term.

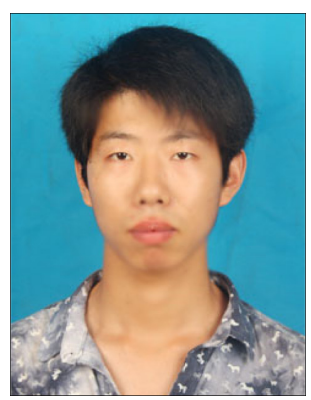

Haixiang Zhang, he is a postgraduate student of Xi'an University of Science and Technology, mainly studying disaster prevention and mitigation engineering, ancient engineering and geotechnical engineering.

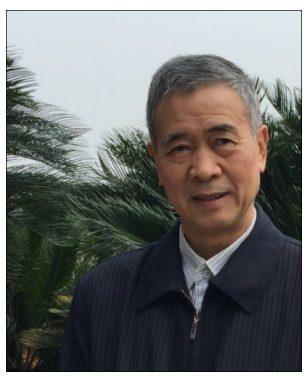

Zhifa Yang, he is a research fellow at the Institute of Geology and Geophysics, Chinese Academy of Sciences. He was secretariat general and managing director of the 4th and 5th Chinese Society of Rock Mechanics and Engineering. He is engaged in the study of theory, methods, techniques and applications of the intersection of two disciplines between engineering geology and rock mechanics for long term, the new research direction of engineering geomechanics information research on ancient engineering was opened for the first time and important research results were achieved by him. 